\title{
SVC Application of Metallurgical Industry Based on self-fitting control technology
}

\author{
Daiyan Wang ${ }^{1}$, Hai Wang ${ }^{2}$, Boyu $X^{3}{ }^{3}$, Shi Yang ${ }^{4}$, Dong $X u^{5}$, Qiang Wang ${ }^{1}$, \\ Hao Long ${ }^{1}$, Yanzhao Guo ${ }^{1}$, Lei Tian ${ }^{1}$ \\ ${ }^{1}$ Rongxin Power Electronic Co., Ltd., Anshan, Liaoning 114051, China \\ ${ }^{2}$ State Grid Liaoning Electric Power Supply Co.,Ltd. Shenyang Power Supply Branch,Shenyang, \\ Liaoning,110811, China \\ ${ }^{3}$ State Grid Liaoning Electric Power Supply Co.,Ltd. Tieling Power Supply Branch, Tieling, \\ Liaoning,112000, China \\ ${ }^{4}$ State Grid Liaoning Electric Power Supply Co.,Ltd. Fushun Power Supply Branch, Fushun, \\ Liaoning , 113008, China \\ ${ }^{5}$ State Grid Liaoning Electric Power Supply Co.,Ltd. Kangping Power Supply Branch, Kangping, \\ Liaoning,110500, China
}

Keywords: SVC, TCR, Adaptive Frequency Technology

\begin{abstract}
SVC is a world-recognized mature and effective dynamic reactive power compensation technology, has been used widely in the world. Through the efforts for more than a decade, Chinese manufacturers have mastered complete SVC technology, own independent intellectual properties, have exported products to Vietnam, Malaysia, India, Brazil and other countries successively. In fact, most overseas customers of SVC are still in developing countries, due to weak power grid architecture, relatively backward overall technical level, a SVC has to overcome many difficulties never encountered in China for long-term stable operation in those countries. This paper takes an example of Rongxin Power Electronic Co., Ltd. that is headquartered in Anshan, China, in the arc furnace power quality control project of a large steel works in India, the paper introduced major problems in the project implementation, and how the technicians solved the problems, finally guaranteed effective compensation of reactive power required by the steel works, solved power quality problems such as voltage fluctuation, flicker and harmonic pollution. The typical project provides precious experience and reference for many Chinese manufacturers to implement SVC project in foreign countries later.
\end{abstract}

\section{Introduction}

Arc furnace is one of the main power consuming equipments in steel works, it is a non-linear load, generates a series of adverse effect on the power grid, for example, serious three-phase unbalance in the power grid, negative sequence current and higher harmonics, and voltage distortion, even flicker in severe cases, will also cause low power factor. Usha Martin Limited is a large iron and steel company in India, has four high power arc furnaces installed, so it encounters many power quality problems. Later, this steel works utilizes SVC to provide reactive current to the system quickly, so as to stabilize bus grid voltage, increase active power output of smelting plant, increase production efficiency, reduce the impact of flicker to the maximum extent. The steel works also utilizes split phase reactive power compensation of SVC to eliminate three-phase unbalance caused by the arc furnace, filter out harmful higher harmonic, increase power factor.

Fig. 1 shows main wiring diagram of SVC compensation system, TCR+FC type, TCR adopts typical delta connection, voltage of the high voltage bus is $132 \mathrm{kV}$, after stepped down by 132 $\mathrm{kV} / 33 \mathrm{kV}$ transformer, it is connected with $33 \mathrm{kV}$ bus via vacuum circuit breaker, SVC system is hung on $33 \mathrm{kV}$ bus. $33 \mathrm{kV}$ bus has the load of totally 4 arc furnaces, 4 groups of filters, Fig. 1 only shows one arc furnace load, one group of filter. 


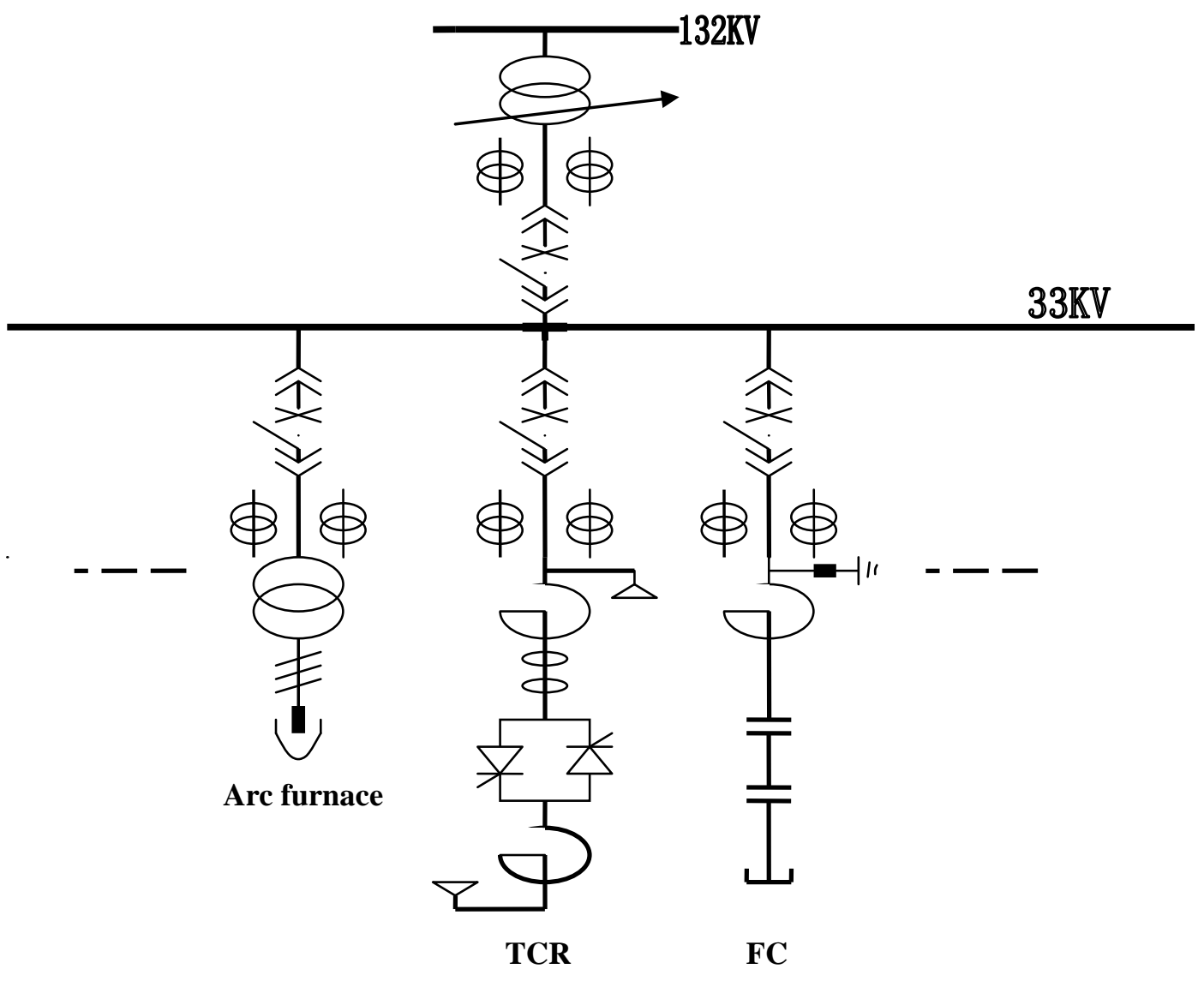

Fig. 1 SVC Main Wiring Diagram

\section{SVC operating principles and control strategy}

1) the composition and operating principles of TCR are shown in Fig.2: basic structure of TCR includes two anti-parallel thyristors and reactor in series, as shown in Fig.2(a). The thyristors work in turn in the positive and negative half cycles of supply voltage, when control angle of the thyristor $\alpha$ is between $90^{\circ}$ and $180^{\circ}$, thyristor is controlled for conduction (full conduction when control angle is $90^{\circ}$, full cutoff at $180^{\circ}$ ). At basically constant grid voltage, increase of the control angle will decrease TCR current, decrease inductive reactive power of the device; on the contrary, decrease of control angle will increase TCR current, increase inductive reactive power of the device. As far as fundamental component of the current is concerned, TCR is equivalent to an adjustable susceptance.

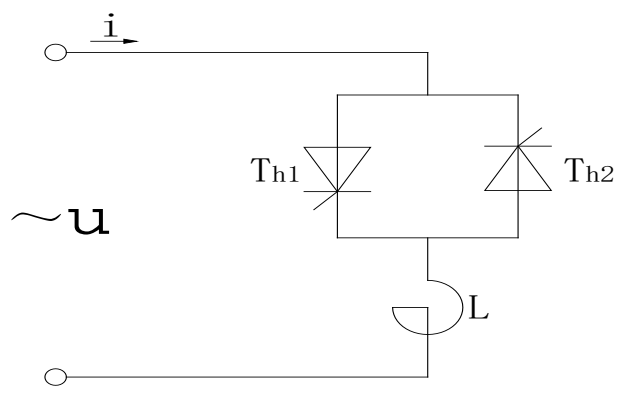

(a)TCR single-phase diagram

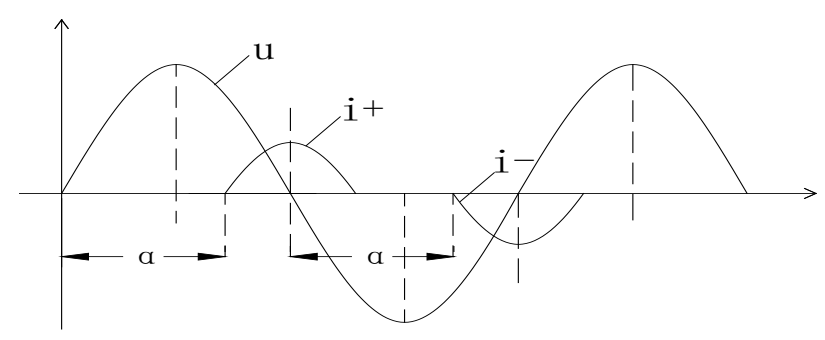

(b)TCR single phase voltage and current waveform

Fig. 2 TCR Schematic Diagram

It may be known from the analysis of Fig. 2 that,

Amplitude of fundamental wave is: $\quad I_{1 m}=B_{L}(\alpha) U_{m}$ 
Therefore, $B_{L}(\alpha)$ is adjustable fundamental frequency susceptance. When $\alpha=\pi / 2$, thyristor realizes full conduction, $B_{L}(\alpha)$ reaches its maximum value $1 / X$; when $\alpha=\pi, B_{L}(\alpha)$ reaches its minimum value zero. In a word, TCR must have a control system, which determines conductive moment, and sends trigger pulse to the thyristor.

\section{SVC control strategy}

1) the strategy of open loop control is relatively simple, mostly used for load compensation, for example, detect reactive power of the load to control the TCR to generate equal reactive power, thus the reactive power provided by power supply is zero, so as to meet the purpose of power factor compensation or improvement of voltage regulation. But accuracy of open loop control strategy is a bit low, interference immunity is poor.

2) control strategy for this project is a closed loop control strategy of follow-up system, it takes reactive power of the load Qf as reference signal, while reactive power of the load is changing, the system enables reactive power compensation to change in the same rule, keeps reactive deviation of input load within the specified scope, after linear processing, trigger angle of the thyristor may be calculated to control inductive reactive power of TCR compensation, so that power factor of the user grid could meet the expected index stably.

\section{Adaptive frequency technology}

Standard frequency of power system in China is $50 \mathrm{~Hz}$, normal standard frequency of power system is specified as $50 \mathrm{~Hz} \pm 0.2 \mathrm{~Hz}$, when system capacity is low, it may be broadened to $50 \mathrm{~Hz} \pm 0.5 \mathrm{~Hz}$. But grid frequency in India is not particularly stable, frequency fluctuation is relatively large. When grid frequency changes greatly, the Chinese-made SVC could not track such quick frequency changes very quickly, Fourier transform will generate deviation, thus generate large reactive error, this brings about difficulty to the tracking compensation of reactive power.

In order to adapt to relatively large changes in grid frequency, get better compensation effect, the SVC controller for arc furnaces of the steel works in India adopts adaptive frequency technology (as shown in adaptive synchronous sampling module in Fig. 3). Control system tracks the changes in grid frequency automatically, sampling calculation and compensation is adjusted according to real time frequency, so as to get accurate control effect.

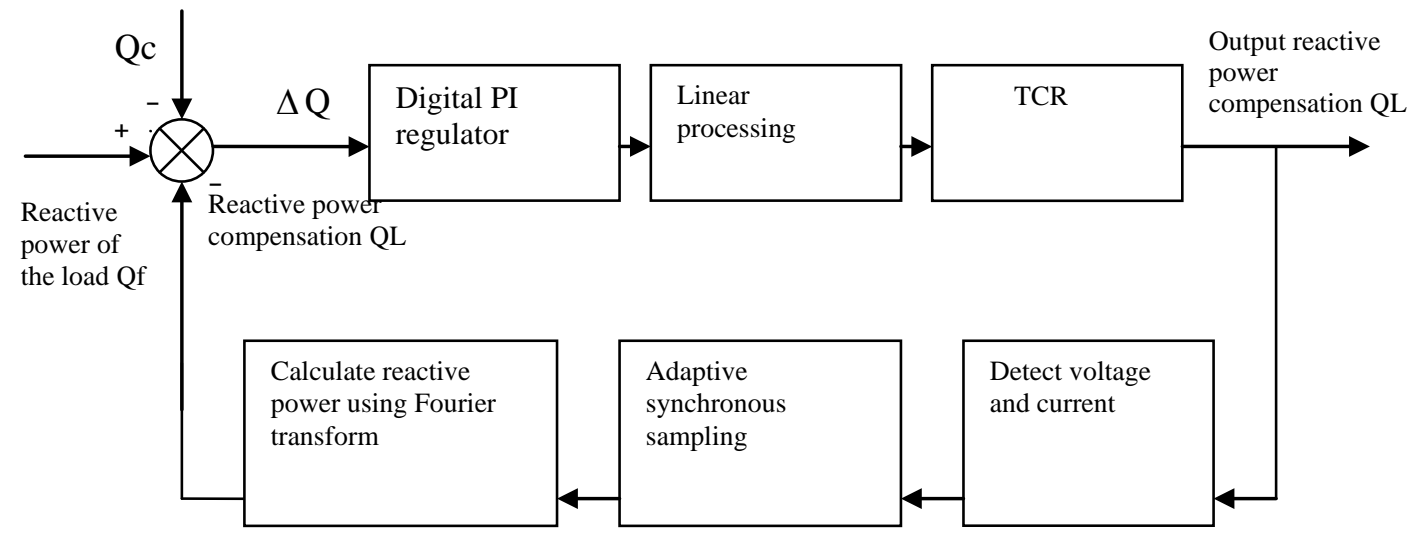

Fig. 3 TCR Control Flow Chart Based on Adaptive Frequency Technology

\section{Global remote monitoring system}

For some foreign customers who have higher requirements, global remote SVC monitoring system may be installed. Both customer and manufacturer may view operating parameters, curve, historical records, fault record of SVC equipment easily and intuitively, it also supports network transmission and remote monitoring. 


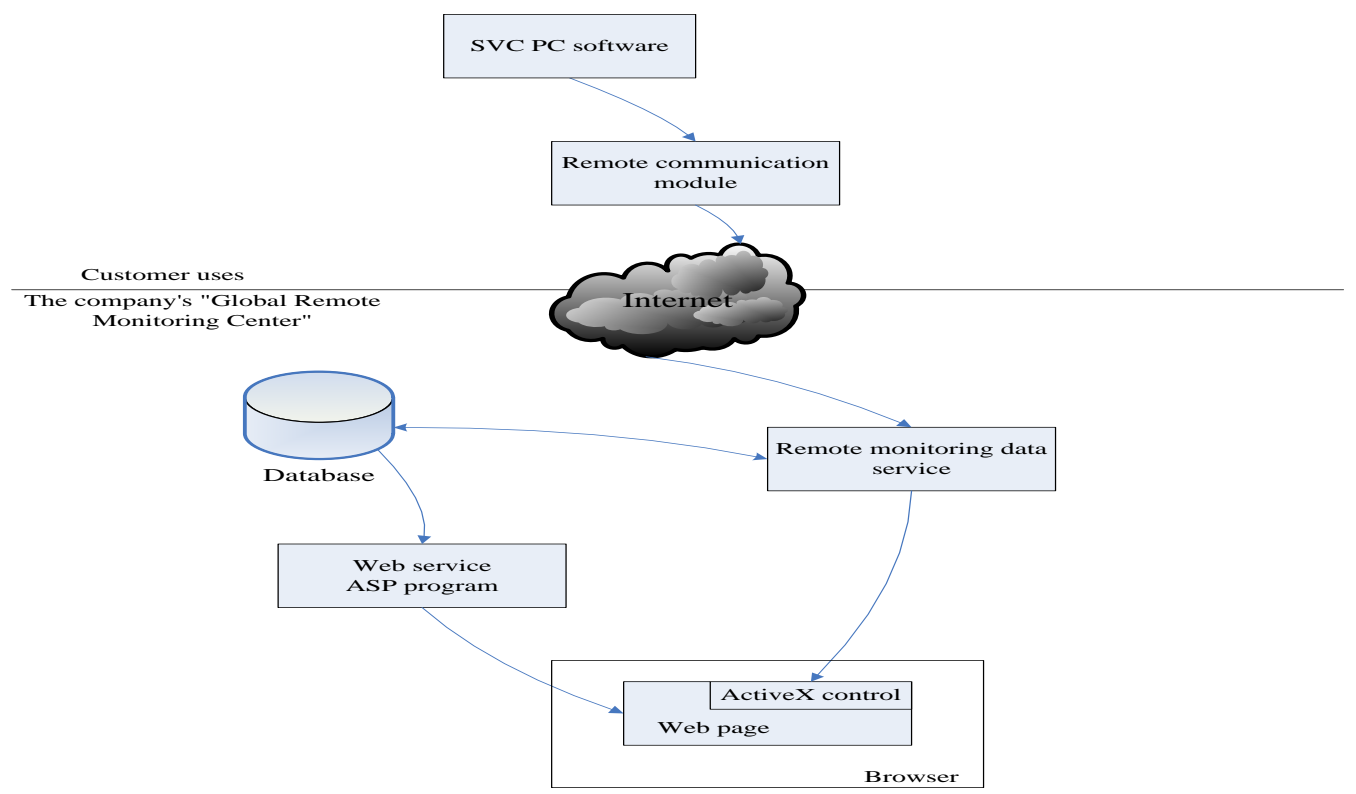

Fig. 4 SVC Global Remote Monitoring System

This system has the following functions:

(1) realizes bidirectional voice intercom. ( i.e. direct dialog between the control center and field)

(2) realizes real time data access, monitors field equipment around the clock.

(3) realizes multi-menu access to the same site, performs multi-angle, multi-directional monitoring for field equipment.

(4) the control center could manage the information acquisition and distribution of all sites in a unified way.

Onsite video monitoring pictures fed back from India are shown in Fig. 5, totally three monitoring pictures, which are thyristor valve block chamber, water cooling chamber, main control room from top to bottom, from the left to the right in turn, the fourth picture has no video signal, is reserved.

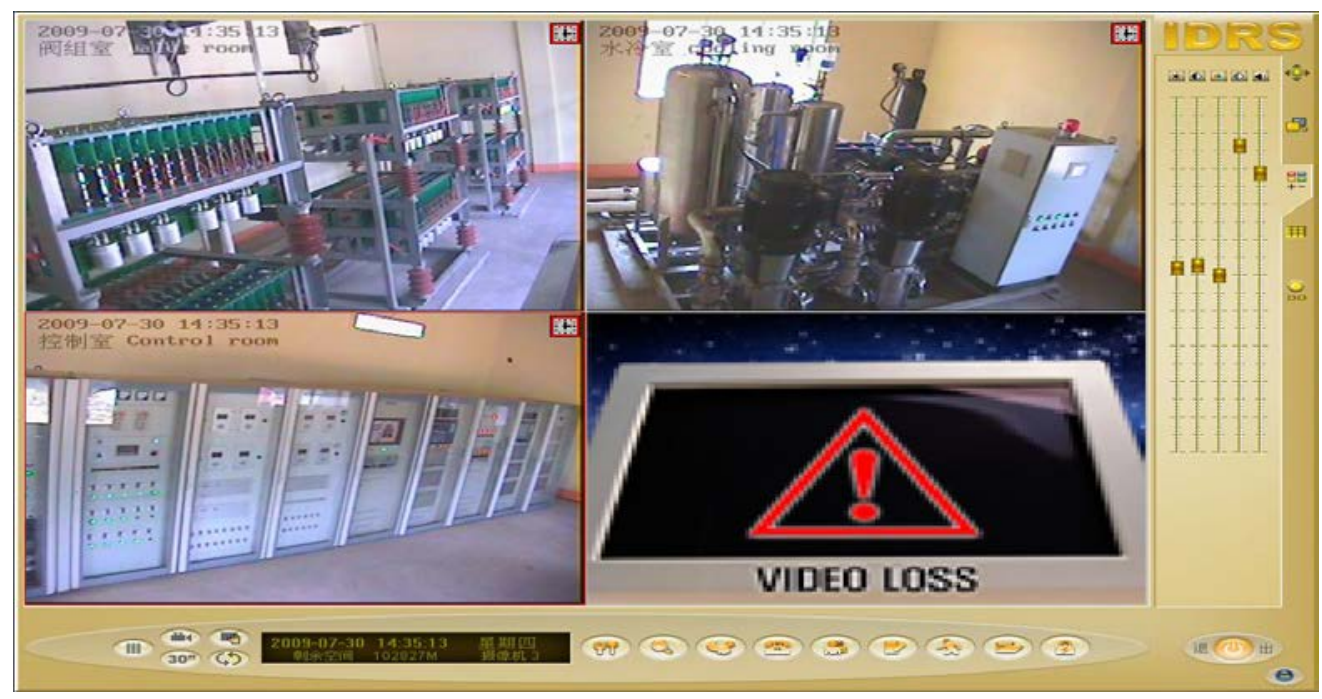

Fig. 5 Video Surveillance on Site 


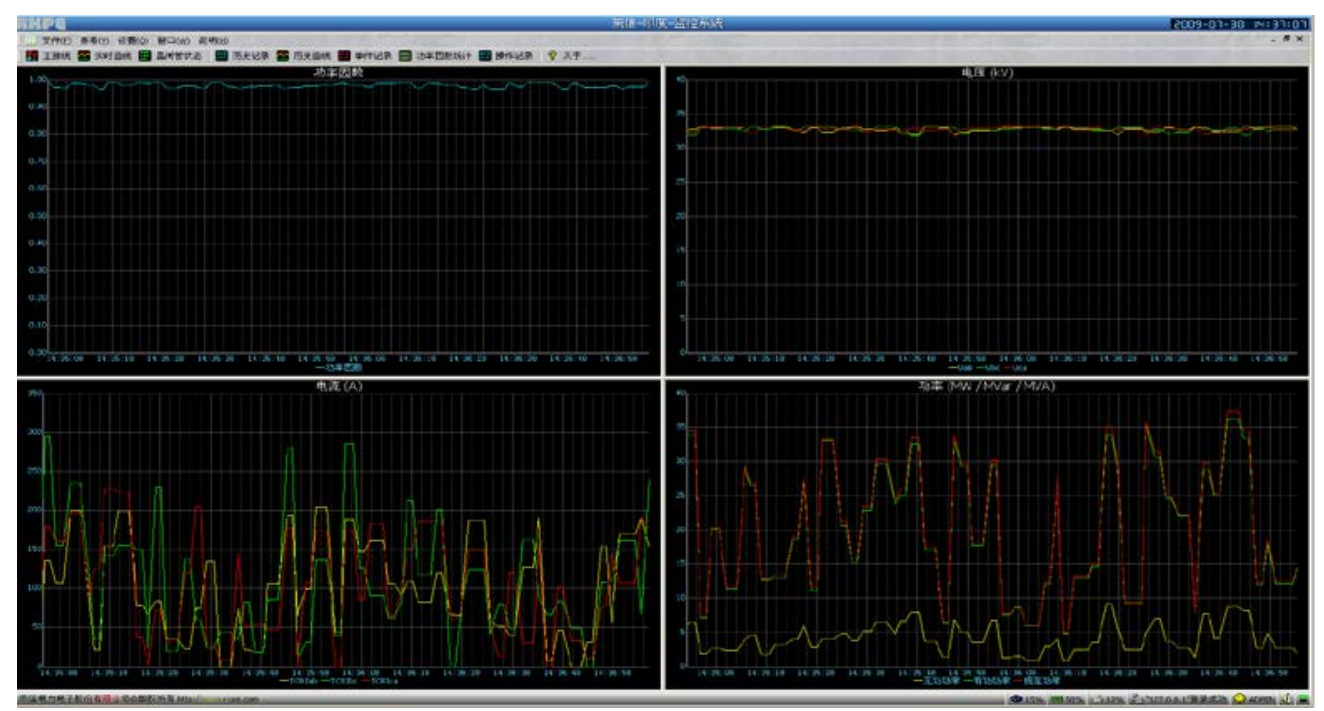

Fig. 6 Main Interface of SVC Real Time Curve

Fig. 6 shows power factor curve, three-phase voltage curve, TCR three-phase current curves (TCRIab,TCRIbc,TCRIca), power curves (including apparent power curve, active power curve, reactive power curve) from the left to the right in turn, the relationship between parameters may be compared intuitively in the form of curve, curves may be recorded in real time around the clock.

\section{Analysis of the voltage stability effect}

During stable operation of 4 arc furnaces, comparison of effective voltage of $33 \mathrm{kV}$ system before and after SVC is put into operation is shown in the table. It should be mentioned that: the data in Table 1 show minimum voltage of $33 \mathrm{kV}$ system in heavy duty.

It may be seen from the data in Table 1 that: in heavy duty, voltage drop is $6.6 \%$, while after SVC is put into operation, voltage drop is $1.2 \%$, could meet national standard requirements. Thus it can be seen that, after SVC is put into operation, voltage stability effect is obvious

Table 1 Comparison of Line Voltage on 33 kV Side Before And After SVC Is Put Into Operation

\begin{tabular}{|l|l|l|l|}
\hline & $\begin{array}{l}\text { Light-duty (SVC is not } \\
\text { put into operation) }\end{array}$ & $\begin{array}{l}\text { Heavy-duty (SVC is not } \\
\text { put into operation) }\end{array}$ & $\begin{array}{l}\text { Heavy-duty (SVC is } \\
\text { put into operation) }\end{array}$ \\
\hline AB voltage $(\mathrm{kV})$ & 33.3 & 32.0 & 33.2 \\
\hline BC voltage $(\mathrm{kV})$ & 33.2 & 32.5 & 32.8 \\
\hline CA voltage $(\mathrm{kV})$ & 33.2 & 32.8 & 32.5 \\
\hline
\end{tabular}

\section{Analysis of reactive compensation effect}

Comparison of the effective current in phase A, B, C of $33 \mathrm{kV}$ system before and after SVC is put into operation is shown in Table 2.

Table 2 Comparison of Current on 33 kV Side Before and After SVC Is Put Into Operation

\begin{tabular}{|l|l|l|}
\hline & $\begin{array}{l}\text { Heavy-duty (SVC is not put into } \\
\text { operation) }\end{array}$ & $\begin{array}{l}\text { Heavy-duty (SVC is put into } \\
\text { operation) }\end{array}$ \\
\hline Phase A current (A) & 621 & 425 \\
\hline Phase B current (A) & 594 & 463 \\
\hline Phase C current (A) & 603 & 451 \\
\hline
\end{tabular}

It may be seen from Table 2 that, after SVC is put into operation, bus current decreases obviously, because, in the current, reactive current has been compensated, thus the impact of reactive current is reduced. It can be seen that, after SVC is put into operation, the effect of reactive compensation is very obvious. 


\section{Comparison of harmonic current}

It may be seen from Table 3 that, after the filters are put into operation, distortion factor of bus current is reduced obviously. Harmonic is filtered out by harmonic channels, current distortion factor could meet customer requirements. Thus it can be seen that, after FC is put into operation, filtering effect is very obvious.

Table 3 Comparison of 33kV Injecting Harmonic Current Before and After the Filters (FC) Are Put Into Operation

\begin{tabular}{|l|l|l|}
\hline Harmonic content/\% \\
\hline Harmonic order & $\begin{array}{l}\text { Heavy-duty (SVC is not put into } \\
\text { operation) }\end{array}$ & $\begin{array}{l}\text { Heavy-duty (SVC is put into } \\
\text { operation) }\end{array}$ \\
\hline 2 & 8.20 & 0.56 \\
\hline 3 & 15.30 & 0.42 \\
\hline 4 & 3.50 & 0.37 \\
\hline 5 & 11.90 & 0.90 \\
\hline \multicolumn{4}{|l|}{$2.0-3.5$} \\
\hline
\end{tabular}

\section{Power factor compensation}

It may be seen from Table 4 that, before SVC is put into operation, power factor is only 0.61 in heavy duty; after SVC is put into operation, power factor maintains above 0.96 . Thus it can be seen that, after SVC is put into operation, power factor increases obviously

Table 4 Comparison of Power Factor on 33 kV Side Before and After SVC Is Put Into Operation

\begin{tabular}{|l|l|l|}
\hline \multicolumn{4}{|c|}{ Power factor } \\
\hline Test group & $\begin{array}{l}\text { Heavy-duty (SVC is not put into } \\
\text { operation) }\end{array}$ & $\begin{array}{l}\text { Heavy-duty (SVC is put into } \\
\text { operation) }\end{array}$ \\
\hline 1 & 0.61 & 0.98 \\
\hline 2 & 0.65 & 0.99 \\
\hline 3 & 0.58 & 1 \\
\hline 4 & 0.53 & 0.99 \\
\hline 5 & 0.70 & 0.98 \\
\hline Average value & 0.61 & 0.988 \\
\hline
\end{tabular}

The following conclusion may be reached through analysis of the statistical data before and after SVC project is put into operation in Usha Martin Limited, India:

(1) use of SVC increases equipment availability, reduces capacity of main transformer, saves cost;

(2) after SVC is put into operation, electricity cost is saved, equipment investment cost may be returned generally within 1.5-3 years. Use of SVC purifies power supply, increases power quality. Reactive power basically does not exist in the system, active power increases, reactive current decreases greatly, so line loss decreases;

(3) after SVC is put into operation, service life of other electrical equipments (transformer, motor) in the company is extended, failure rate of other equipments is reduced;

\section{Conclusion}

SVC may increase power factor of electrical installations, improve power quality of the grid under different system conditions. At the same time, thanks to mature technology, good compensation effect, high performance/price ratio, such device has been used widely. Considering specific parameters of foreign power grid, it is a must to adopt advanced algorithm to meet different site conditions, further improve SVC compensation performance, and expand application fields of SVC. 


\section{References}

[1] Jiang Qirong, Xie Xiaorong, Chen Jianye. Shunt Compensation of Power System -- Structure, Principle, Control and Application [M]. Beijing: China Machine Press, 2004. 8.

[2] Wang Zhaoan, Yang Jun, Liu Jinjun. Harmonic suppression and reactive power compensation [M]. Beijing: China Machine Press, 2004. 2.

[3] Dusan raonic,Ljubisa Stankovic,Dusan petranovic,”Adaptive Control System for Hubrid SVC," control Applications,1995,proceedings of the $4^{\text {th }}$ IEEE Conference on 28-29 Step 1995 Page(s):378-382.

[4] Sang-Joon Lee, Jun-Koo Kang, Seung-Ki Sul.A New Phase Detecting Method for Power Conversion Systems Consid-ering Distorted Conditions in Power System[A].Industry Applications Conference, Conf. Record of the IEEE'99, 1999: 2167-2172.

[5] Shu Zeliang, Guo Yuhua, Tang Jian. Implementation of Three-Phase Phase-Locked Loop Based on FPGA [J]. Power and electronic technology, 2005, 39(6): 126-128. 